This manuscript is a preprint and has been submitted for consideration in the volume 'Campi Flegrei' - Springer collection Active Volcanoes of the World. It has not undergone peer review. Subsequent versions of this manuscript may have different content as a result of the review process. If accepted, the final version of this manuscript will be available via the 'Peer-reviewed Publication DOI' link. We welcome feedback, so please feel free to contact chiara.montagna@ingv.it or leave a comment.

\title{
The dynamics of the Campi Flegrei caldera magma chamber.
}

Chiara P. Montagna chiara.montagna@ingv.it@ volcpm Paolo Papale paolo.papale@ingv.it Antonella Longo antonella.longo@ingv.it Istituto Nazionale di Geofisica e Vulcanologia,

Sezione di Pisa 
Th2 is is a non-peer reviewed preprint submitted to 'Campi Flegrei' - Springer Active Volcanoes of the World collection

\title{
The dynamics of the Campi Flegrei caldera magma chamber.
}

\author{
Chiara P. Montagna, Paolo Papale, Antonella Longo \\ Istituto Nazionale di Geofisica e Vulcanologia \\ Sezione di Pisa \\ chiara.montagna@ingv.it; paolo.papale@ingv.it; antonella.longo@ingv.it
}

\begin{abstract}
The Campi Flegrei volcanic system is certainly a remarkable case study for what concerns magma chamber dynamics. In fact, its magmatic and volcanic history appears to have been largely driven by chamber processes like fractional crystallization, magma mixing, and volatile degassing. These processes have been intensely investigated with a variety of approaches. Here we employ physicomathematical modelling and numerical simulations in order to study the dynamics of magma convection and mixing in a vertically extended, geometrically complex, compositionally heterogeneous magmatic system representing a schematic simplification of an overall picture emerging from previous studies at Campi Flegrei. Although clearly a simplification, a number of first order characteristics of possible real magmatic systems at Campi Flegrei are accounted for, including the more chemically evolved, partially degassed nature of magmas emplaced at shallow depths, and the likely occurrence of multiple reservoirs with different depth, size and shape which can be connected at certain stages during system evolution, allowing deeper, $\mathrm{CO}_{2}$-rich magmas to rise and rejuvenate the shallow magmas.
\end{abstract}

\section{The magmatic system of Campi Flegrei.}

The magmatic system underneath the Campi Flegrei volcanic complex can be reconstructed based on information from various geophysical surveys as well as analysis of eruptive products of past eruptions.

Analyses of seismic records allow to infer the position and location of fluids within the rock medium (Judenherc and Zollo, 2004; Zollo et al., 2008; De Siena et al., 2010; Masterlark et al., 2010; Chouet and Matoza, 2013). A seismic reflection horizon at around $8 \mathrm{~km}$ depth possibly identifies the top of a partially molten region, probably as wide as some tens of kilometers in the horizontal direction, most likely representing a huge magmatic sill (Judenherc and Zollo, 2004; Zollo et al., 2008).

A variety of evidence suggests that small batches of magma have been forming throughout the caldera history (De Siena et al., 2010; Di Renzo et al., 2011). Crystallized magma bodies, sized less than $1 \mathrm{~km}^{3}$, have been recognized by processing offshore seismic lines, at depths ranging between less than 1 and $6 \mathrm{~km}$ (C. Fac- 
Th3 is is a non-peer reviewed preprint submitted to 'Campi Flegrei' - Springer Active Volcanoes of the World collection 3

cenna, in: Papale and Civetta, 2007); fluid-rich batches interpreted as partially molten magma have been identified by seismic attenuation tomography in the same depth range (De Siena et al., 2010). Reconstructed phase equilibria for the Agnano Monte Spina eruption, as well as $\mathrm{H}_{2} \mathrm{O}$ and $\mathrm{CO}_{2}$ contents in melt inclusions from Minopoli2, Fondo Riccio, and Agnano Monte Spina confirm that magmas had been residing at virtually any depth smaller than about $9 \mathrm{~km}$ (Roach, 2005; Mangiacapra et al., 2008; Arienzo et al., 2010). Small, shallow magma bodies have been identified as actively involved in past eruptions, which at least in some cases shortly followed the arrival of volatile-rich, less differentiated magmas from depth (Arienzo et al., 2009, 2010; Fourmentraux et al., 2012).

The composition of the erupted products ranges from shoshonitic to trachytic to phonolitic; geochemical analyses on melt inclusions suggest a variety of processes going on during inter-eruptive periods including magma recharge, intra-chamber mixing, entrapment of phenocrysts left from previous eruptions, etc. (Arienzo et al., 2010).

From all the above, a schematic picture of the Campi Flegrei magmatic system can be derived (Figure 1). It includes the deep magmatic sill containing the less evolved, $\mathrm{CO}_{2}$-rich shoshonitic magma; and more or less persistent features, such as dikes, fractures or conduits, linking the deep reservoir to shallower, degassed, crystal-richer batches of magma. Shallower reservoirs contain magmas with compositions from trachyte to phonolite. Mingling and mixing of shallow magma with others coming from depth is thought to constitute a recurrent process in the Campi Flegrei volcanism, often invoked as the main trigger of a new eruption (Arienzo et al., 2011; Fourmentraux et al., 2012). Eruptive products preserve the signature of such process, and provide clues as to time scales of mixing, that in most cases appear to last only hours to days before the eruption (Perugini et al., 2010). The regional and/or local stress regimes allows the deep magmas to rise to shallow levels, either along established pathways or cracking the host rocks and creating new ones. When the rising magma encounters a molten or partially molten region, the residing magma gets rejuvenated and mixes with the incoming one (Bachmann and Bergantz, 2003). At Campi Flegrei, magmas rising from depth are typically rich in gas, especially $\mathrm{CO}_{2}$ (Mangiacapra et al., 2008; Arienzo et al., 2010). When such magmas reach an already established reservoir where more dense and viscous magma is residing, they tend to rise under the action of buoyancy forces. The compositionally different magmas mix first physically, and, on longer time scales, chemically, producing intermediate compositions (Arienzo et al., 2009; Tonarini et al., 2009; Perugini et al., 2010; Di Renzo et al., 2011). 
Th4 is is a non-peer reviewed preprint submitted to 'Campi Flegrei' - Springer Active Volcanoes of the World collection

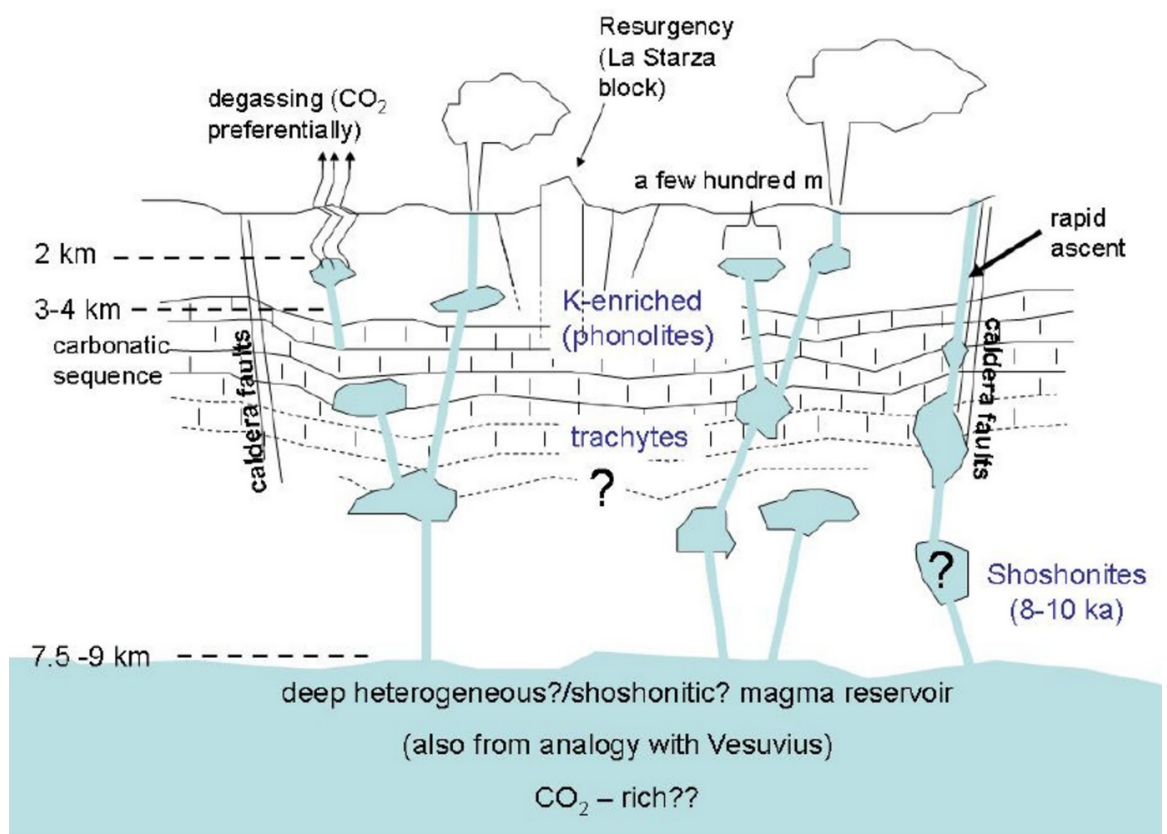

Figure 1: Scheme of the shallow magmatic system beneath the Campi Flegrei caldera (Papale and Civetta, 2007)

\section{Physical model.}

\subsection{Magma chamber dynamics.}

Magma chamber dynamics are governed by several microscopic and macroscopic physical and chemical processes, such as periodic magma injection, mixing and mingling of different magmas, magma differentiation due to crystal fractionation and melt segregation, heat and mass transfer between the phases and with the surrounding rocks. The quantitative study of magma dynamics is complicated by the uncertainties about the characteristics of the magmatic system, which is out of direct observation. As a consequence, modeling approaches are usually directed to capture first order aspects of magma chamber dynamics.

One of the first numerical models for mixing of incompressible homogeneous magmas due to diffusion and thermal-compositional convection was developed by Oldenburg et al. (1989, and references therein). Crystallization in magma chambers undergoing convection is described by the enthalpy formulation in Spera et al. (1995) and Kuritani (2004). The dynamics of compressible/incompressible homogeneous bubbly magma driven by exsolution of water and/or caldera subsidence have been simulated by Folch et al. (1999, 2001, and references therein). Trial et al. (1992) modeled the withdrawal of incompressible magma driven by pressure forces associated with chamber replenishment. The passive degassing of 
Th5 is is a non-peer reviewed preprint submitted to 'Campi Flegrei' - Springer Active Volcanoes of the World collection5

a stratified magma chamber and the compositional convection driven by vesiculation and crystal settling have been studied by Simakin and Botcharnikov (2001). Rejuvenation of a crystal mush by gas arriving from depth can be modeled as a flow through a porous medium (Bachmann and Bergantz, 2006); thermal convection can be included (Annen et al., 2008).

\subsection{Numerical approach.}

Our physical-mathematical model (Longo et al., 2012) describes the time-dependent 2D dynamics of a compressible-to-incompressible multicomponent mixture consisting of liquid (or crystal suspension) in thermodynamic equilibrium with an $\mathrm{H}_{2} \mathrm{O}+\mathrm{CO}_{2}$ gas phase at the local conditions of pressure, temperature and composition. The numerical algorithm used in the solution of the conservation equations is based on an extension of the finite element formulation by Hauke and Hughes (1998) to include multicomponent fluids (Longo et al., 2006), allowing the investigation of processes involving mixing of fluids, chemical changes, and phase transitions. The algorithm consists of a space-time discretization with Galerkin least-squares and discontinuity capturing terms, with third order accuracy in time and space. This method allows the simulation of both compressible and incompressible flow dynamics (Shakib et al., 1991; Chalot and Hughes, 1994; Hauke and Hughes, 1998), and it is effective in stabilizing the numerical solution without introducing excessive numerical diffusion. A large number of problems can be solved, such as natural and forced convection, shock waves and their interaction with contact discontinuities, evolution of internal interfaces in incompressible or compressible flows, and bubbly flows with evaporation or gas dissolution. The conservation equations for the mass of single components and momentum of the whole mixture, together with the gas-liquid thermodynamic equilibrium model and the constitutive equations for mixture properties (density and viscosity), are discretized and solved for the primitive variables pressure, velocity, temperature, and concentration of components. Magmas are described as ideal mixtures with components that may be either in the liquid or gaseous state, with instantaneous phase change according to the non-ideal multicomponent $\mathrm{H}_{2} \mathrm{O}+\mathrm{CO}_{2}$ saturation model of Papale et al. (2006). The solid phase (suspended crystals) is taken into account in the computation of mixture properties. Gas bubbles are assumed to be undeformable, a good approximation if the bubble size is smaller than $\sim 10 \mu \mathrm{m}$ (Marchetti et al., 2004). This corresponds to a gas volume of 5 to $50 \%$ for bubble number densities in the range $10^{14}$ to $10^{15} \mathrm{~m}^{-3}$. The role on the relevant properties (density and viscosity) of dissolved water and of dispersed gas and solid phases, and the mutual roles of $\mathrm{H}_{2} \mathrm{O}$ and $\mathrm{CO}_{2}$ in affecting their saturation contents, are accounted for. Mixture density is calculated using the Lange (1994) equation of state for the liquid phase, real gas properties and standard mixture laws for multiphase fluids. Mixture viscosity (under the assumption of Newtonian rheology) is computed through standard rules of mixing (Reid et al., 1977) for one phase mixtures and with a semi-empirical relation (Ishii and Zuber, 1979) in order to account for 
Th6 is is a non-peer reviewed preprint submitted to 'Campi Flegrei' - Springer Active Volcanoes of the World collection

the effect of non-deformable gas bubbles. Liquid viscosity is modeled as in Giordano et al. (2008), and it depends on liquid composition and dissolved water content.

\subsection{System setup.}

In order to understand the dynamics of magmas beneath the Campi Flegrei caldera, we simplify the magmatic system trying to retain its most peculiar features. We specifically aim at exploring the mixing process, and the dependence of its efficiency and time scales on the simulation conditions. The evolution of overpressure in the different portions of the magmatic system is analyzed in a separate study (Papale et al., in prep.).

We model the injection of $\mathrm{CO}_{2}$-rich, shoshonitic magma coming from a deep reservoir into a shallower, much smaller chamber, containing more evolved and partially degassed phonolitic magma. The deep reservoir is schematized as a sill; the geometry of the shallow chamber has been varied from oblate to prolate in a set of simulations, as shown in Figure 2. Initial conditions for the simulated cases are reported in Table 1.
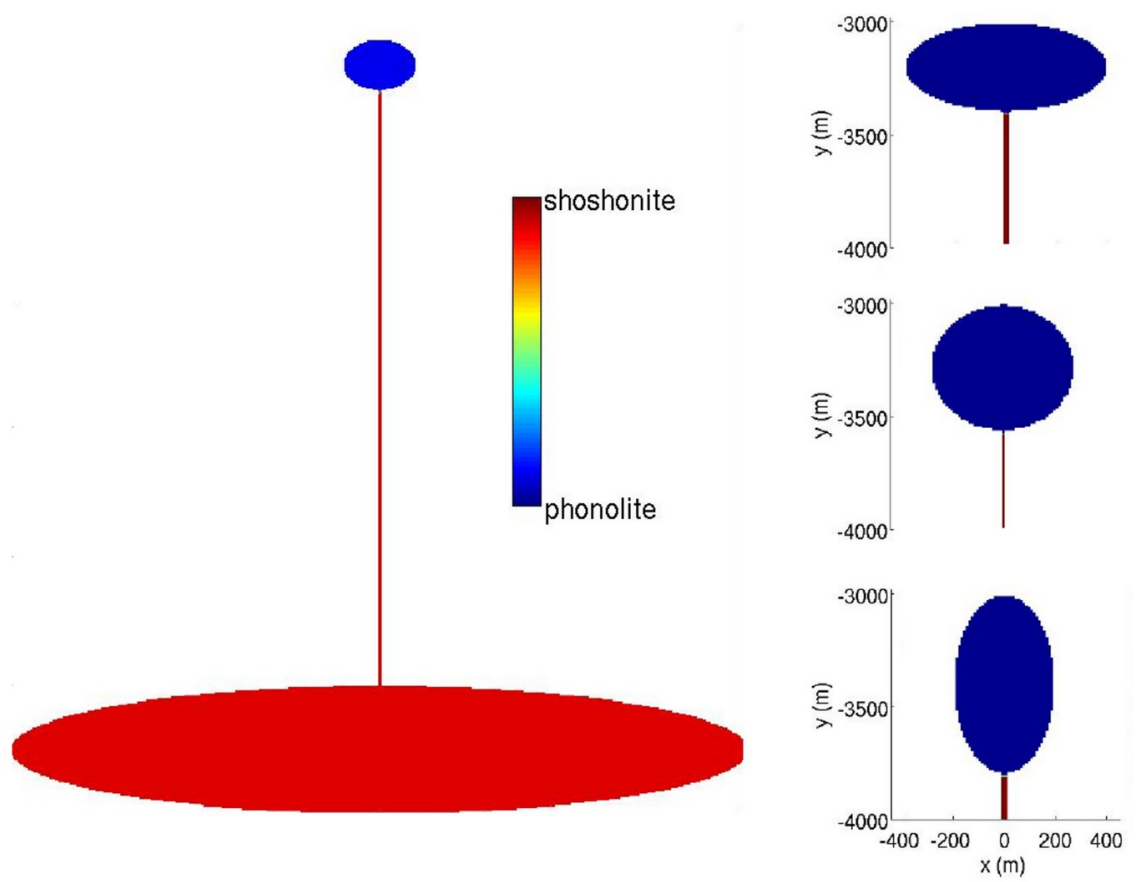

Figure 2: The whole simulated sistem alongside the three different geometrical settings for the shallower magma chamber at Campi Flegrei. Top: Horizontally elongated, sill-like chamber. Center: Circular chamber. Bottom: Vertically elongated, dike-like chamber 


\begin{tabular}{|c|c|c|c|c|c|c|c|c|c|c|}
\hline \multirow{2}{*}{$\begin{array}{c}\text { Simulation } \\
\text { no. }\end{array}$} & \multicolumn{5}{|c|}{ Assumed initial conditions } & \multicolumn{5}{|c|}{ Calculated initial conditions } \\
\hline & $\begin{array}{c}\mathrm{CO}_{2} \text { shoshon- } \\
\text { ite } \\
(\text { wt \%) }\end{array}$ & $\begin{array}{c}\mathrm{CO}_{2} \text { phonolite } \\
\text { (wt \%) }\end{array}$ & $\begin{array}{c}\mathrm{H}_{2} \mathrm{O} \text { shoshon- } \\
\text { ite } \\
(\text { wt } \%)\end{array}$ & $\begin{array}{c}\mathrm{H}_{2} \mathrm{O} \text { phono- } \\
\text { lite } \\
(w \mathrm{t} \%)\end{array}$ & $\begin{array}{c}\text { Geometry of } \\
\text { shallow } \\
\text { chamber }\end{array}$ & $\begin{array}{l}\text { Density con- } \\
\text { trast at initial } \\
\text { interface } \\
\left(\mathrm{kg} / \mathrm{m}^{3}\right)\end{array}$ & $\begin{array}{l}\text { Gas volume } \\
\text { at initial in- } \\
\text { terface, } \\
\text { shoshonite } \\
\text { (vol \%) }\end{array}$ & $\begin{array}{l}\text { Gas volume } \\
\text { at initial in- } \\
\text { terface, } \\
\text { phonolitie } \\
\text { (vol \%) }\end{array}$ & $\begin{array}{l}\text { Gas volume } \\
\text { at system top } \\
\text { (vol \%) }\end{array}$ & \begin{tabular}{|c} 
Gas volume \\
at system bot- \\
tom \\
$($ vol \%)
\end{tabular} \\
\hline 1 & 1 & 0.3 & 2 & 2.5 & Oblate & 30 & 10 & 5 & 7 & 3 \\
\hline 2 & 1 & 0.3 & 2 & 2.5 & Prolate & 20 & 8 & 4 & 7 & 3 \\
\hline 3 & 1 & 0.3 & 2 & 2.5 & Circular & 25 & 9 & 5 & 7 & 3 \\
\hline 4 & 1 & 0.1 & 2 & 1 & Oblate & 120 & 9 & 2 & 2 & 3 \\
\hline 5 & 1 & 0.1 & 2 & 1 & Prolate & 140 & 8 & 2 & 2 & 3 \\
\hline
\end{tabular}

Table 1: List of simulations and their initial conditions. 
Th8 is is a non-peer reviewed preprint submitted to 'Campi Flegrei' - Springer Active Volcanoes of the World collection

The top of the deep reservoir is at $8 \mathrm{~km}$ depth, and its horizontal and vertical semiaxes measure $4 \mathrm{~km}$ and $0.5 \mathrm{~km}$, respectively. The shallow reservoir has its top at 3 $\mathrm{km}$ below the surface; its surface area is kept to $0.25 \cdot 10^{6} \mathrm{~m}^{3}$, representing a volume of magma of order a few tenths of $\mathrm{km}^{3}$. The oxides composition of the two magmas is detailed in Table 2 .

Table 2: Oxides compositions for the two end-member magmas.

\begin{tabular}{|l|l|l|l|l|l|l|l|l|l|l|}
\hline & $\mathrm{SiO}_{2}$ & $\mathrm{TiO}_{2}$ & $\mathrm{AlO}_{2}$ & $\mathrm{Fe}_{2} \mathrm{O}_{3}$ & $\mathrm{FeO}$ & $\mathrm{MnO}$ & $\mathrm{MgO}$ & $\mathrm{CaO}$ & $\mathrm{Na}_{2} \mathrm{O}$ & $\mathrm{K}_{2} \mathrm{O}$ \\
\hline Shoshonite & 0.48 & 0.012 & 0.16 & 0.021 & 0.063 & 0.0014 & 0.10 & 0.12 & 0.028 & 0.015 \\
\hline Phonolite & 0.54 & 0.0060 & 0.20 & 0.016 & 0.032 & 0.0014 & 0.017 & 0.068 & 0.047 & 0.079 \\
\hline
\end{tabular}

At the initial time, the two magmas are placed in contact at the bottom of the shallow chamber (top of the feeding dyke) (Figure 2). Because of the higher volatile content thus lower overall density of the deeper magma, the system is gravitationally unstable. Therefore, the deep magma tends to rise into the shallow chamber, pushing the resident magma down through the feeding dike.

We explored different set-ups in order to highlight the roles played by the geometry of the magmatic system and by the extent of previous degassing of the shallow magma. Keeping the upper chamber top at a depth of $3 \mathrm{~km}$ and its $2 \mathrm{D}$ crosssectional area, we changed its geometry from a sill to a circle and to a vertically elongated, dike-like ellipsoid. For the two ellipsoidal chambers, we also reduced the volatile content of the shallow phonolitic magma to $1 \mathrm{wt} \% \mathrm{H}_{2} \mathrm{O}$ and $0.1 \mathrm{wt} \%$ $\mathrm{CO}_{2}$, compared to $2.5 \mathrm{wt} \% \mathrm{H}_{2} \mathrm{O}$ and $0.3 \mathrm{wt} \% \mathrm{CO}_{2}$ of the previous set of simulations. The deep shoshonitic magma contains in all cases $2 \mathrm{wt} \% \mathrm{H}_{2} \mathrm{O}$ and $1 \mathrm{wt} \%$ $* \mathrm{CO}_{2}$ (Table 1). It is worth noting that such quantities are total volatile amounts, and they are distributed between liquid and gas phases according to the local conditions and the saturation model of Papale et al. (2006). The simulated systems are closed, with fixed boundaries. The effect of wall-rock elasticity on the chamber dynamics is neglected, as it is assumed to cause small pressure changes with respect to those originating from the magma dynamics.

\section{Results.}

The simulations reveal with unprecedented detail interesting patterns of magma convection and mixing taking place in the upper chamber + feeding dyke domains. In order to illustrate those patterns, we refer to a reference simulation (corresponding to case 4 in Table 1), and describe the other cases through comparison with the reference one.

The reference simulation takes into account a situation where the shallow chamber had previously degasses efficiently. As a consequence, the density con- 
Th9 is is a non-peer reviewed preprint submitted to 'Campi Flegrei' - Springer Active Volcanoes of the World collection9

trast between the two magma types at initial magma interface is relatively large, corresponding to about $120 \mathrm{~kg} / \mathrm{m}^{3}$. The shallow reservoir is horizontally elongated.
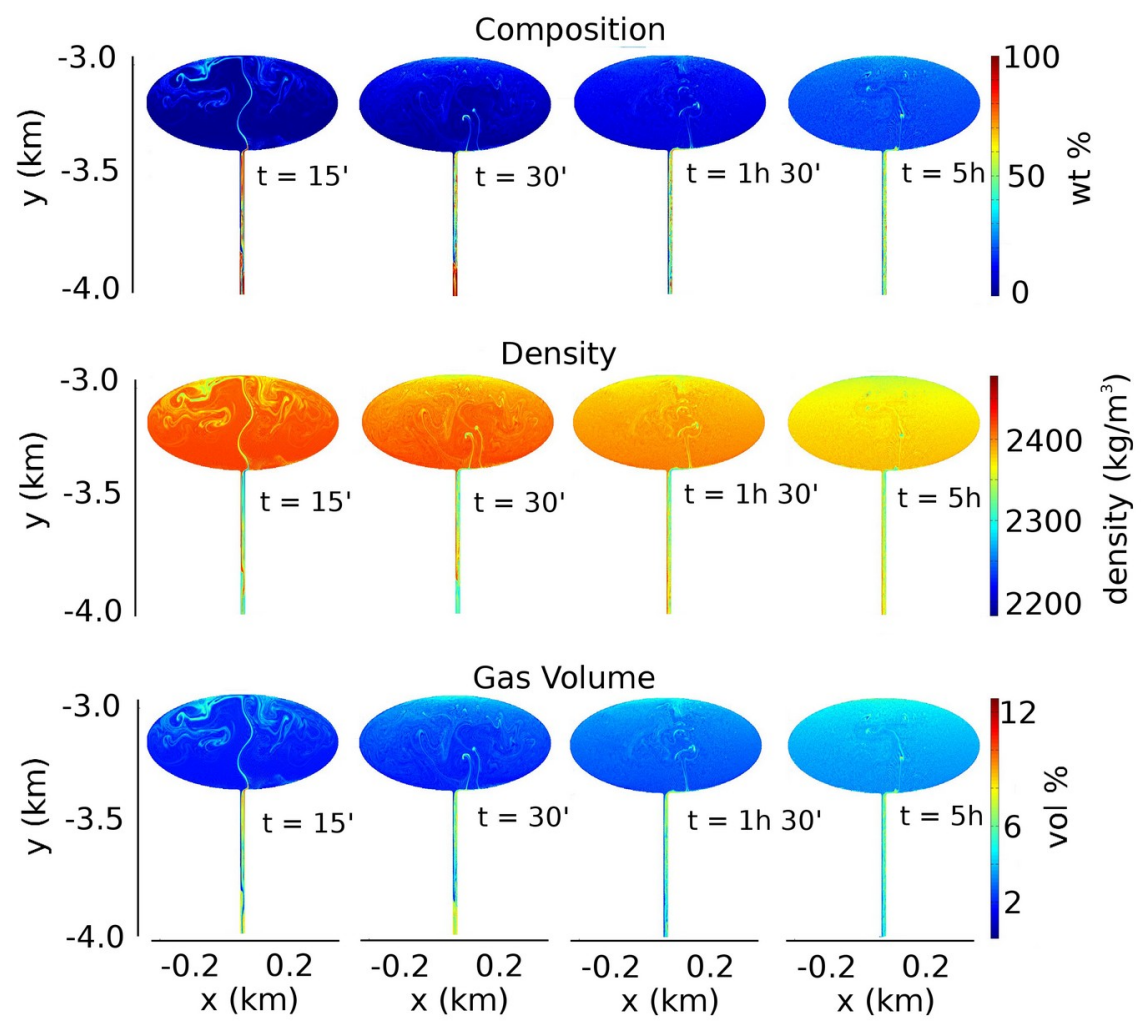

Figure 3: Snapshot of composition, density and gas volume fractions at different simulated times in the shallower part of the system

Figure 3 summarizes the results in terms of the relevant quantities - composition, density and gas volume fraction - that are shown at four different times up to 5 hours of real time. Soon after the start of the simulation, disruption of the initial interface by buoyancy forces produces a series of discrete plumes of light magma rising through the shallow chamber and reaching its top after having developed complex velocity fields. At the same time, part of the dense magma originally hosted in the shallow chamber sinks into the feeding dyke. Intense mixing originates at the dyke level, so that no pure shoshonitic end-member can be found in the shallow chamber; the rising plumes are rather made of a mixture with 30 to 50 wt \% deep component. In our framework, only mechanical mixing is considered, as chemical reactions apart from volatile exsolution/dissolution are not implemented in the numerical scheme. Therefore, mixing at the scale of the simulation, 
Th10 is is a non-peer reviewed preprint submitted to 'Campi Flegrei' - Springer Active Volcanoes of the World collection

with maximum resolution of order $1 \mathrm{~m}$, refers to mechanical mingling rather than chemical mixing. The simulated dynamics suggests a complex pattern of convection and mixing (or mingling) whereby the original dense magma rapidly mixes up with the volatile-rich, lighter magma coming from depth at chamber bottom or dyke level. The original phonolite carried down into the dyke mixes up with the shoshonite; the mixed magma is overall lighter than the magma above it or in its immediate surroundings, therefore part of the initially sunk magma is carried up again into the shallow chamber, while other portions continue to sink down into the dyke. This complex process originates a compositional, density, and gas volume stratification inside the chamber, with maximum gas volumes at chamber top of about $6 \mathrm{vol} \%$. In the meantime, the original density contrast at chamber bottom is disrupted and a smoother and smoother density profile is created, so that the convective process tends to slow down in time. Figure 4 shows the time distribution of the efficiency of convection for all performed simulations, defined as the initial total mass in the shallow chamber minus the same quantity at the reference time, normalized to the initial amount so to allow direct comparison of the different cases.

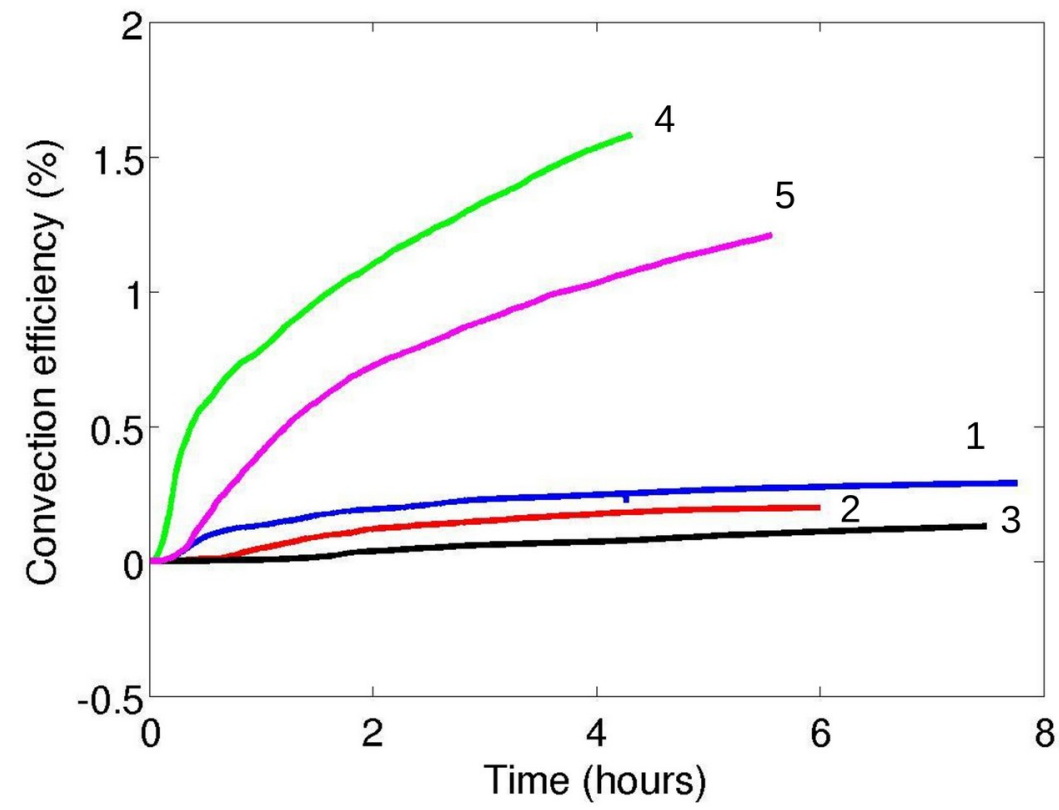

Figure 4: Convection efficiency in the shallow reservoir for the different simulations as function of time. The simulation number is the same as in Table 1

Figure 4 highlights a number of relevant aspects of the simulated dynamics. First of all, in all cases the total mass in the shallow chamber decreases with time as a consequence of partial substitution of the initial dense phonolite with the lighter gas-rich shoshonite. In the most efficient case, corresponding to the refer- 
Th11 is is a non-peer reviewed preprint submitted to 'Campi Flegrei' - Springer Active Volcanoes of the World collection 11

ence case described above, the total mass in the shallow chamber has decreased by less than $2 \mathrm{wt} \%$ after about 5 hours of convection and mixing. Second, the efficiency of convection increases substantially with the extent of degassing of the magma initially residing in the chamber (cases 1,2 and 3 correspond to lower degassing extent, see Table 1). Third, convection and mixing tend to smooth down with time, as revealed by the progressive decrease of the slopes. As a matter of fact, $>80 \%$ of the dense, degassed magma initially residing in the chamber remains at chamber level after waning of the convective process (as in case 1, where an asymptotic trend clearly emerges). Thus, the complex patterns of convection and mixing described above are such that most of the degassed magma is not carried down to larger depths when a new stable profile has been created. While shallow chamber degassing creates unstable conditions by increasing the density of the magma at shallow levels, the ingression of small amounts of volatile-rich magma rapidly re-establishes a new 'equilibrium'. The new overall stability is a dynamic condition: even at the longest simulated times we still observe small batches of mixed magma entering the chamber while other batches sink into the dyke, overall keeping a more or less constant balance of total mass and of single magmatic components in the chamber. 
Th12 is is a non-peer reviewed preprint submitted to 'Campi Flegrei' - Springer Active Volcanoes of the World collection
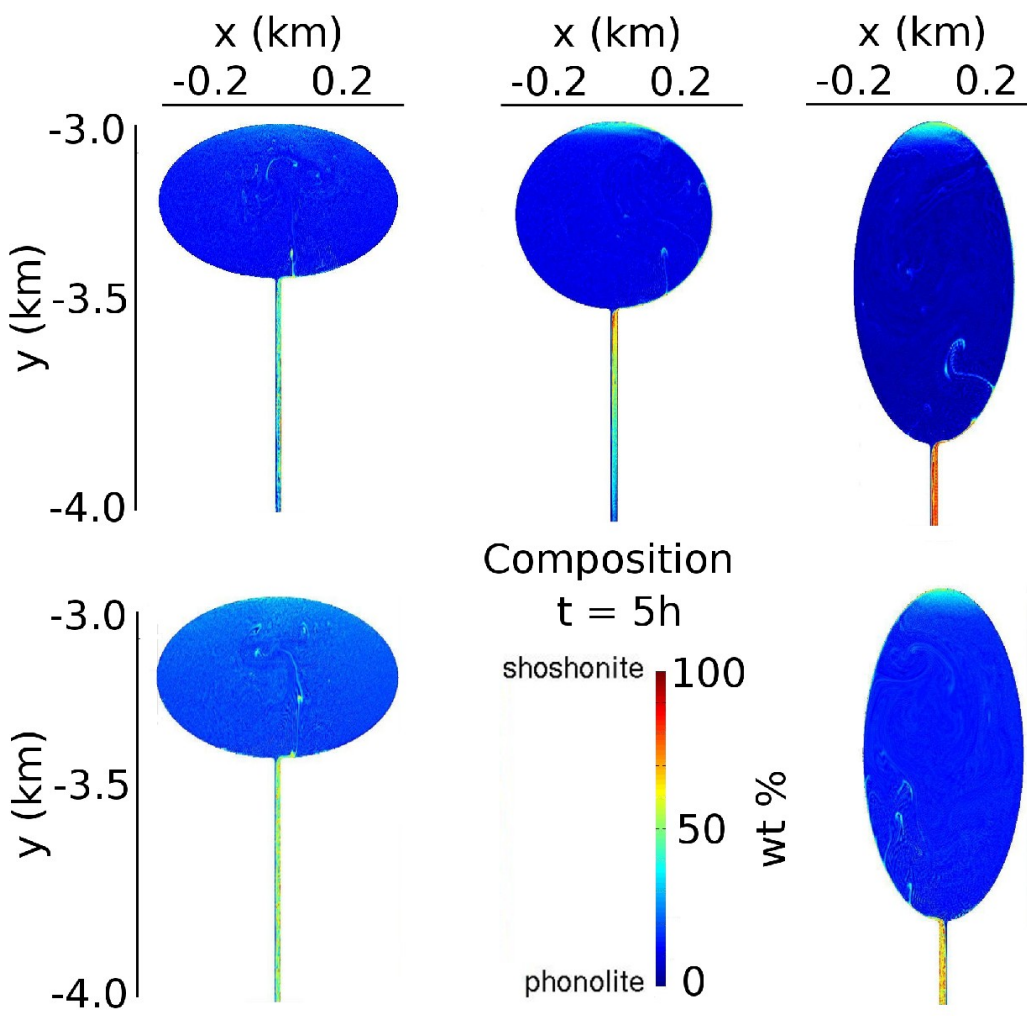

Figure 5: Composition in the upper chamber after 5 hours of simulated time. From left to right, top to bottom, order of simulations as in Table 1: Simulation 1, low density contrast, horizontal chamber. Simulation 2, low density contrast, circular chamber. Simulation 3, low density contrast, vertical chamber. Simulation 4, reference simulation, high density contrast, horizontal chamber. Simulation 5, high density contrast, vertical chamber

Finally, the trends in Figure 4 show that the efficiency of convection depends on the shallow chamber geometry in such a way that it decreases when its horizontal dimension also decreases. This is expected, as the efficiency of natural convection depends on the system dimension perpendicular to the driving force represented by gravity. That is also visible from the colour plots in Figure 5, which show a progressive deeper blue (that is, lower proportion of deep magmatic component) when moving from oblate to circular to prolate chamber geometry. At the same time, however, the more prolate geometries result in more pronounced accumulation of volatile-rich deep component at the chamber top, thus more pronounced chamber stratification.

It is also remarkable that the plumes of lighter magma tend to rise through the chamber following significantly different patterns. In fact, such plumes tend to stick to the chamber walls for much longer distances in prolate geometries, devel- 
Th13 is is a non-peer reviewed preprint submitted to 'Campi Flegrei' - Springer Active Volcanoes of the World collection 13

oping roughly one single convective cell in the chamber. That optimizes convection, thus partly balances the effects of decreased horizontal chamber size diminishing the extent to which the convection efficiency is reduced when moving from oblate to prolate geometries.

\section{Discussion}

This study focuses on the convection and mixing dynamics occurring in a shallow chamber when it is intersected by a dyke carrying more primitive, volatilerich (especially $\mathrm{CO}_{2}$ ) magma from a deeper reservoir. The system conditions refer to a general situation appropriate for the volcanism of Campi Flegrei, dominated by the emplacement of relatively small magma chambers at shallow levels, repeatedly recharged by deeper magma while undergoing shallow system degassing. The volcanic products reveal magma mixing mostly from melt-crystal (Roach, 2005; Rutherford, in Papale and Civetta 2007) and isotopic (Arienzo et al., 2009, and references therein) disequilibrium, as well as from melt inclusions within crystals (Arienzo et al., 2010). While mixing between different magmas is a widespread occurrence at Campi Flegrei, magmatic end-member components are usually not identified at the macroscopic scale in the volcanic products, especially for the deeper, less chemically evolved components the presence of which emerges only from detailed chemical and petrographic analyses. On the other hand, time scales of magma mixing can be quite short, of the order of hours to days, as it is revealed by both time-scales of melt-crystal disequilibrium (Roach, 2005) and by the application of a diffusive fractionation model of trace elements to a number of relevant eruptions in the Campi Flegrei history (Perugini et al., 2010).

Although a full comparison is limited by the resolution of the computational grid, which is of order $1 \mathrm{~m}$, the present numerical simulations provide a fully con sistent picture: in all simulated cases, the deep, less evolved, volatile-rich endmember magma involved in the mixing process is rapidly lost as an individual component, while magma mixing results in a stratified but substantially laterally homogeneous (at the resolved spatial scale) composition on a short time-scale of a few to 10 hours. The simulations additionally suggest a relevant role of magma mixing at the feeding dyke level, and highlight complex patterns whereby the partially degassed magma originally hosted at shallow levels can sink down into the dyke, mix with the rising volatile-rich magma, then re-enter into the chamber as a mixture component masking the end-member characteristics of the deep rejuvenating magma.

The present numerical simulations are limited by the huge computational time they require, therefore, only some hours of real time have been explored till now. A conceptual extrapolation to much longer times is allowed by the fact that in some of the simulated cases, and specifically in case 1 corresponding to the longest simulated time (about 8 hours), a condition is reached where the initial gravitational instability is completely destroyed and new dynamically stable conditions are established. Thus, the simulation describes an entire mixing cycle in which the 
Th14 is is a non-peer reviewed preprint submitted to 'Campi Flegrei' - Springer Active Volcanoes of the World collection

initial density contrast is totally removed and a new dynamic equilibrium is reached. All other simulations show the same tendency, as it is suggested by the progressive flattening of the convection efficiency curves in Figure 4, although over the simulated times a stable condition is in most cases approached but not reached. The trigger for the whole process is provided by the fact that the shallow magma is initially partially degassed, therefore its density is larger, at same pressure conditions, that the density of the magma rising from depth. This is the origin of the gravitational instability in our initial conditions.

Magmatic bodies emplaced at shallow level are known to degas efficiently, as a consequence of relatively large gas volumes at low pressure conditions and brittle rock mechanics allowing the generation of cracks providing pathways for gas escape towards the surface. In the specific case of Campi Flegrei, an abundant magmatic gas component is recognized in the fumaroles of La Solfatara crater (Caliro et al., 2007; Moretti et al., 2012), that globally discharge about 1500 tons/day of $\mathrm{CO}_{2}$ in the atmosphere (Caliro et al., 2007). The final condition in all our simulations is the establishment of a gas-rich cap at the top of the shallow chamber (Figures 3 and 4). It is expected that over a longer time this would feed a new efficient degassing phase. Large oscillations in the $\mathrm{CO}_{2}$ content of the fumarolic gases at $\mathrm{La}$ Solfatara are well known (Chiodini et al., 1996), and more recently, similar oscillations have been proposed to occur in their magmatic component (Moretti et al., 2013). These oscillations follow the major seismic and deformation crisis at Campi Flegrei in 1982-84, and they are possibly related to the emplacement of a small magmatic body at 3-4 km depth as revealed by recent seismic attenuation tomography (De Siena et al., 2010).

An overall picture emerges from the above: after the emplacement of a small magma body at shallow depth, open system degassing feeding the fumarolic gases (and possibly, partial crystallization of magma) increases magma density and triggers the arrival of new gas-rich, light magma batches from a deep reservoir, likely along the same pathways that brought the magma to a shallow level. This in turn gives rise to magma convection and mixing, that re-establishes dynamically stable conditions over a short time-scale of hours to a few days (increasing with the extent of shallow system degassing). New gas-rich, $\mathrm{CO}_{2}$-rich magma is accumulated at the top of the shallow chamber, and over a longer time scale of months to years, open system degassing (and crystallization) increases again the density in the upper system, triggering a new episode of magma injection and repeating the process. Such a sequence can be repeated several times, each time rejuvenating the shallow magmatic system through the injection of small batches of volatile-rich magma from larger depths, and providing new gas that will slowly escape from the system and feed the fumarolic system.

\section{Conclusions}

The present numerical simulations, and the overall picture described above, are consistent with a number of observations of the Campi Flegrei volcanism (and to 
Th15 is is a non-peer reviewed preprint submitted to 'Campi Flegrei' - Springer Active Volcanoes of the World collection 15

an extent, of several other volcanic products worldwide), including i) the chemical oscillations observed in the fumarolic gases, that appear to punctuate long-term degassing patterns; ii) the chemical zoning in crystals, that marks oscillations in the P-T-X conditions at crystallization levels; iii) the presence of melt inclusions in crystals that are in chemical disequilibrium with their host; iv) the dispersion of volatile contents in melt inclusions that hardly mark simple closed or open system degassing patterns, rather they suggest a widespread occurrence of convection and mixing (a well-studied example is reported for Kilauea in Barsanti et al., 2009; the melt inclusion data for the Agnano Monte Spina eruption at Campi Flegrei (Arienzo et al., 2010) show similar patterns); v) the tendency towards rapid homogenization of magmas upon mixing, preventing macroscopic identification of end-member components; vi) the time-scales of magma mixing as revealed by separate approaches like melt-crystal disequilibrium and trace element diffusive fractionation modeling.

\section{References}

Annen C, Pichavant M, Bachmann O, Burgisser A (2008) Conditions for the growth of a long-lived shallow crustal magma chamber below Mount Pelee volcano (Martinique, Lesser Antilles Arc). J Geophys Res 113:B07209. doi: 10.1029/2007JB005049

Arienzo I, Civetta L, Heumann A, Horner GW, Orsi G (2009) Isotopic evidence for open system processes within the Campanian Ignimbrite (Campi Flegrei, Italy) magma chamber. B Volcanol 71:285-300. doi: 10.1007/s00445-0080223-0

Arienzo I, Moretti R, Civetta L, Orsi G, Papale P (2010) The feeding system of Agnano Monte Spina eruption (Campi Flegrei, Italy): Dragging the past into present activity and future scenarios. Chem Geol 270:135-147. doi: 10.1016/ j.chemgeo.2009.11.012

Arienzo I, Heumann A, Horner GW, Civetta L, Orsi G (2011) Processes and timescales of magma evolution prior to the Campanian Ignimbrite eruption (Campi Flegrei, Italy). Earth Planet Sc Lett 306:217-228. doi: 10.1016/ j.eps1.2011.04.002

Bachmann O, Bergantz GW (2003) Rejuvenation of the Fish Canyon magma body: A window into the evolution of large-volume silicic magma systems. Geology 31:789-792

Bachmann O, Bergantz GW (2006) Gas percolation in upper-crustal silicic crystal mushes as a mechanism for upward heat advection and rejuvenation of 
Th16 is is a non-peer reviewed preprint submitted to 'Campi Flegrei' - Springer Active Volcanoes of the World collection

near-solidus magma bodies. J Volcanol Geoth Res 149:85-102. doi: 10.1016/ j.jvolgeores.2005.06.002

Barsanti M, Papale P, Barbato D, Moretti R, Boschi E, Hauri EH, Longo A (2009) Heterogeneous large total $\mathrm{CO}_{2}$ abundance in the shallow magmatic system of Kilauea volcano, Hawaii. J Geophys Res 144:B12201

Caliro S, Chiodini G, Moretti R, Avino R, Granieri D, Russo M, Fiebig J (2007) The origin of the fumaroles of La Solfatara (Campi Flegrei, South Italy). Geochim Cosmochi Ac 71:3040-3055. doi: 10.1016/j.gca.2007.04.007

Chalot F, Hughes TJR (1994) A consistent equilibrium chemistry algorithm for hypersonic flows. Comput Methods Appl Mech Engrg 112:25-40

Chiodini, G, Cioni R, Magro G, Marini L, Panichi C, Raco B, Russo M (1996) Gas and water geochemistry Chemical and isotopic variations of Bocca Grande fumarole (Solfatara volcano, Phlegrean Fields) Acta Vulcanologica 8:228-232

Chouet BA, Matoza RS (2013) A multi-decadal view of seismic methods for detecting precursors of magma movement and eruption. J Volcanol Geoth Res 252:108-175,. doi: 10.1016/j.jvolgeores.2012.11.013

De Siena L, Del Pezzo E, Bianco F (2010) Seismic attenuation imaging of Campi Flegrei: Evidence of gas reservoirs, hydrothermal basins, and feeding systems. J Geophys Res 115:1-18. doi: 10.1029/2009JB006938

Di Renzo V, Arienzo I, Civetta L, D’Antonio M, Tonarini S, Di Vito MA, Orsi G (2011) The magmatic feeding system of the Campi Flegrei caldera: Architecture and temporal evolution. Chem Geol 281:227-241. doi: 10.1016/ j.chemgeo.2010.12.010

Folch A, Vazquez M, Codina R, Martì J (1999) A fractional-step finite-element method for the Navier-Stokes equations applied to magma-chamber withdrawal. Comput Geosci 25:263-275,. doi: S0098-3004(98)00164- 2

Folch A, Codina R, Martì J (2001) Numerical modeling of magma withdrawal during explosive caldera-forming eruptions. J Geophys Res 106:16,163-16,176

Fourmentraux C, Metrich N, Bertagnini A, Rosi M (2012) Crystal fractionation, magma step ascent, and syn-eruptive mingling: the Averno 2 eruption (Phlegraean Fields, Italy). Contrib Mineral Petr 163:1121-1137. doi: 10.1007/s00410-0120720-1

Giordano D, Russell JK, Dingwell DB (2008) Viscosity of magmatic liquids: A model. Earth Planet Sc Lett 271:123-134

Hauke G, Hughes TJR (1998) A comparative study of different sets of variables for solving compressible and incompressible flows. Comput Methods Appl Mech Engrg 153:1-44

Ishii M, Zuber N (1979) Drag coefficient and relative velocity in bubbly, droplet or particulate flows. AiChE J 25:843-855

Judenherc S, Zollo A (2004) The Bay of Naples (southern Italy): Constraints on the volcanic structures inferred from a dense seismic survey. J Geophys Res 109:B10312. doi: 10.1029/2003JB002876. 
Th17 is is a non-peer reviewed preprint submitted to 'Campi Flegrei' - Springer Active Volcanoes of the World collection 17

Kuritani (2004) Magmatic differentiation examined with a numerical model considering multicomponent thermodynamic and momentum, energy and species trasport. Lithos 74:117-130,. doi: 10.1016/j.lithos.2003.12.007

Lange RA (1994) The effect of $\mathrm{H}_{2} \mathrm{O}, \mathrm{CO}_{2}$ e F on the density and viscosity of silicate melts. Rev Mineral 30:331-369

Longo A, Vassalli M, Papale P, Barsanti M (2006) Numerical simulation of convection and mixing in magma chamber replenished with $\mathrm{CO} 2$-rich magma. Geophys Res Lett 33:L21305. doi: 10.1029/2006GL027760.

Longo A, Barsanti M, Cassioli A, Papale P (2012) A finite element Galerkin/ least-squares method for computation of multicomponent compressible/incompressible flows. Comput Fluids 67:57-71. doi: 10.1016/j.compfluid.2012.07.008

Mangiacapra A, Moretti R, Rutherford M, Civetta L, Orsi G, Papale P (2008) The deep magmatic system of the Campi Flegrei caldera (Italy). Geophys Res Lett 35:L21304. doi: 10.1029/2008GL035550

Marchetti E, Ichihara M, Ripepe M (2005) Propagation of acoustic waves in a viscoelastic two-phase system: influence of gas bubble concentration. J Volcano Geoth Res 137:93-108. doi: 10.1016/j.jvolgeores.2004.05.002

Masterlark T, Haney M, Dickinson H, Fournier T, Searcy C (2010) Rheologic and structural controls on the deformation of Okmok volcano, Alaska: FEMs, InSAR, and ambient noise tomography. J Geophys Res 115:B02409. doi: 10.1029/2009JB006324

Moretti R, Arienzo I, Civetta L, Orsi G, Papale P (2013) Multiple magma degassing sources at an explosive volcano. Earth Planet Sci Lett 367:95-104. doi: 10.1016/j.epsl.2013.02.013

Oldenburg CM, Spera FJ, Yuen DA, Sewell G (1989) Dynamic mixing in magma bodies: Theory, simulations and implications. J Geophys Res 94:92159236

Papale P, Civetta L (2007) INGV-DPC Campi Flegrei 2005-2007. Technical report

Papale P, Moretti R, Barbato D (2006) The compositional dependence of the saturation surface of $\mathrm{H}_{2} \mathrm{O}+\mathrm{CO}_{2}$ fluids in silicate melts. Chem $\mathrm{Geol}$ 229:78-95. doi: 10.1016/j.chemgeo.2006.01.013

Papale P, Longo A, Montagna CP (in prep.) Magma chamber paradox: decompression upon replenishment.

Perugini D, Poli G, Petrelli M, Campos CP, Dingwell DB (2010) Time-scales of recent Phlegrean Fields eruptions inferred from the application of a diffusive fractionation model of trace elements. B Volcanol 72:431-447. doi: 10.1007/ s00445-009-0329-z

Reid RC, Prausnitz J, Sherwood T (1977) The properties of gases and liquids. McGraw Hill, New York

Roach AC(2005) The evolution of silicic magmatism in the post-caldera volcanism of the Phlegrean Fields, Italy. PhD thesis, Brown University 
Th18 is is a non-peer reviewed preprint submitted to 'Campi Flegrei' - Springer Active Volcanoes of the World collection

Shakib F, Hughes TJR, Johan Z (1991) A new finite element formulation for computational fluid dynamics: X. The compressible Euler and Navier-Stokes equations. Comput. Methods Appl Mech Engrg 89:141-219

Simakin A, Botcharnikov R (2001) Degassing of stratified magma by compositional convection. J Volcanol Geoth Res 105:207-214

Spera FJ, Oldenburg CM, Christensen UR, Todesco M (1995) Simulation of convection in the system KAlSi2 O6-CaMgSi2 O6 : Implications for compositionally zoned magma bodies. Am Mineral 80:1188-1207

Tonarini S, D’Antonio M, Di Vito MA, Orsi G, Carandente A (2009) Geochemical and BSrNd isotopic evidence for mingling and mixing processes in the magmatic system that fed the Astroni volcano (4.13.8 ka) within the Campi Flegrei caldera (southern Italy). Lithos 107:135-151. doi: 10.1016/ j.lithos.2008.09.012

Trial AF, Spera FJ, Greer J, Yuen DA (1992) Simulations of magma withdrawal from composizionally zoned bodies. J Geophys Res 97:6713-6733

Zollo A, Maercklin N, Vassallo M, Dello Iacono D, Virieux J, Gasparini P (2008) Seismic reflections reveal a massive melt layer feeding Campi Flegrei caldera. Geophys Res Lett 35(12):L12306. doi: 10.1029/2008GL034242 